\title{
ANTIBACTERIAL EFFECT OF 0.2\% CHLORHEXIDINE AND 1\% CHITOSAN MOUTHWASH ON BACTERIA DURING ORTHODONTIC MINISCREW USE
}

\author{
ERLINA HASRIATI ${ }^{1}$, HARU SETYO ANGGANI ${ }^{2 *}$, MARIA PURBIATI' ${ }^{2}$, ENDANG WINIATI BACHTIAR ${ }^{3}$
}

${ }^{1}$ Orthodontics Residency Program, Faculty of Dentistry, Universitas Indonesia, Jakarta, Indonesia. ${ }^{2}$ Department of Orthodontics, Faculty of Dentistry, Universitas Indonesia, Jakarta, Indonesia. ${ }^{3}$ Department of Oral Biology, Faculty of Dentistry, Universitas Indonesia, Jakarta, Indonesia. Email: haruanggani@yahoo.com

Received: 17 February 2020, Revised and Accepted: 01 June 2020

ABSTRACT

Objective: Inflammation is one of the most common complications observed when using orthodontic miniscrews. Chlorhexidine mouthwash can be used to prevent and reduce the degree of inflammation, but long-term use of this solution may lead to some side effects. This study sought to evaluate the peri-miniscrew antibacterial effect of $1 \%$ chitosan, a biomaterial with antibacterial properties, relative to $0.2 \%$ chlorhexidine mouthwash.

Methods: A randomized, double-blind clinical trial was conducted at the Dental Teaching Hospital and Oral Biology Research Laboratory at the University of Indonesia from February to June 2019. Thirty subjects (25 females and five males) were randomly assigned to rinse with $1 \%$ chitosan $(n=10), 0.2 \%$ chlorhexidine digluconate $(n=10)$, and Aquadest $(n=10)$ in addition to their usual oral hygiene procedure for 4 days. Peri-miniscrew clinical inflammation signs were recorded and peri-miniscrew plaque collected before and after 4 days of rinsing. The total bacterial and red-complex bacteria count in plaque samples were evaluated by a real-time polymerase chain reaction.

Results: Chitosan and chlorhexidine showed antibacterial activity, reducing total bacterial count around orthodontic miniscrews ( $<<0.05$ ). The antibacterial activity of chitosan on total bacteria was not significantly different from that of chlorhexidine ( $\mathrm{p} \geq 0.05$ ). Regarding the antibacterial activity of chitosan on red-complex bacteria, the best result seen was a 58\% bacteria count reduction in Tannerella denticola.

Conclusion: Chitosan has potential antibacterial activity and could be used in mouthwash to maintain peri-miniscrew hygiene.

Keywords: Orthodontic miniscrew, Chitosan, Chlorhexidine, Red-complex bacteria, Mouthwash.

(C) 2020 The Authors. Published by Innovare Academic Sciences Pvt Ltd. This is an open access article under the CC BY license (http://creativecommons. org/licenses/by/4. 0/) DOI: http://dx.doi.org/10.22159/ijap.2020.v12s2.OP-07

\section{INTRODUCTION}

Nowadays, miniscrews have been widely used in orthodontic treatment due to their superiority relative to other anchorage devices. Miniscrews are versatile, easy to install and remove, function independently of the patient's cooperation, and are relatively affordable [1,2]. However, they also bear risks and impart complications that may occur during the installment procedure, orthodontic treatment, and the removal procedure [3]. Inflammation is a common complication that may appear around orthodontic miniscrews. The environment condition around the miniscrew neck - which is dark, anaerobic, and full of nutrition (amino acids and peptides) - promotes anaerobic bacterial growth that may lead to peri-miniscrew inflammation [4].

The previous studies have revealed that the bacteria in peri-implantitis are similar to those that caused the periodontitis [5]. The primary pathogenic bacteria in periodontitis cases in adults mostly include redcomplex bacteria such as Porphyromonas gingivalis, Tanerella forsythia, and Treponema denticola. One of the ways to prevent bacterial growth is by rinsing with an antibacterial mouthwash. Chlorhexidine is the gold standard mouthwash that can be used to prevent and reduce bacterial growth and inflammation [6]. However, the use of chlorhexidine mouthwash on a daily basis may exhibit some side effects, such as oral mucosa irritation, taste perception alteration, burning sensation, and tooth staining [7].

On the other hand, recentstudies have found that chitosan is a biomaterial that possesses antibacterial properties. Chitosan is produced from the deacytelation of chitin, a biopolymer that can be obtained from crustaceans $[8,9]$. However, studies on the antibacterial activity of chitosan as a mouthwash in clinical application remain minimal due to the material's water-insoluble properties. Ibrahim et al. [10] created a chitosan mouthwash solution from microcrystalline chitosan (chitosan that has been modified by minimizing its particle size); their results suggested that $1 \%$ microcrystalline chitosan solution can reduce the bacteria total plate count up to $99.05 \%$. Therefore, this study sought to evaluate the antibacterial effect of $1 \%$ chitosan solution relative to $0.2 \%$ chlorhexidine mouthwash on a bacterial level around orthodontic miniscrews in vivo.

\section{METHODS}

\section{Ethical clearance}

This randomized double-blind clinical trial was conducted at the Dental Teaching Hospital and Oral Biology Research Laboratory at the University of Indonesia from February 2019 to June 2019. The trial was approved by the Ethics Committee of Research at the Faculty of Dentistry, University of Indonesia (ref. no. 4/ethical approval/FKG UI/I/2019). All participants signed the written informed consent before participating in the study.

\section{Subject criteria}

Thirty subjects were randomly assigned to rinse with $1 \%$ chitosan solution $(\mathrm{n}=10), 0.2 \%$ chlorhexidine digluconate mouthwash $(\mathrm{n}=10)$, and Aquadest $(\mathrm{n}=10)$ in addition to their usual oral hygiene procedure for 4 days. The inclusion criteria were orthodontic patients aged 1065 years who have not consumed antibiotics in the past month, with miniscrews (Dual-Top Anchor System; JEIL Med. Corp., Korea) inserted at least 2 weeks before the sampling procedure, who were willing to participate in this study and signed the informed consent form. The exclusion criteria were patients with an allergic history to chitosan and chlorhexidine, those who were systemically compromised, and smokers. 
Clinical procedure and materials

Every subject was instructed to rinse twice a day (after breakfast in the morning and before sleep in the evening) for 4 days with $10 \mathrm{~mL}$ of assigned solution for $30 \mathrm{~s}$. The rinsing procedure was conducted after the usual oral hygiene procedure, which included tooth- and miniscrewbrushing. Subjects were not allowed to rinse/eat/drink for 30 min after the rinsing procedure. The chlorhexidine mouthwash used in this study is commercially available at a $0.2 \%$ chlorhexidine gluconate mouthwash (MINOSEP ${ }^{\circledR}$ PT. Minorock Mandiri, Depok, Indonesia). Separately, the chitosan solution used in this study is also commercially available with a composition of $1 \%$ chitosan with $0.25 \%$ acetic acid $\left(\mathrm{KITOBE}^{\mathrm{TM}}\right.$; Berkah Inovasi Kreatif Indonesia, Bogor, Indonesia). The deacetylation degree (DD) of the chitosan is $85 \%$ with a high molecular weight (MW) (CV. Biochitosan Indonesia, Cirebon, Indonesia). Sterile Aquadest was used as rinsing solution in the control group. All rinsing solution was placed in 30 identical 100 -mL bottles and randomly labeled as one to 30 by the first author's supervisor.

Peri-miniscrew clinical inflammation signs (i.e., redness, swelling, pain, and mobility) were recorded, and peri-miniscrew plaque was collected by a single operator both before and after 4 days of rinsing. Peri-miniscrew redness and swelling were detected visually. Pain was quantified based on the patient's opinion. Miniscrew mobility was evaluated visually with mouth mirror handles [11]. Any orthodontic auxiliaries were removed from the miniscrew, and the surface was air-dried. The selection of samples to be evaluated with real-time quantitative polymerase chain reaction (qPCR) was done by prioritizing miniscrews located in the right buccal of the maxilla from each patient. This location was chosen because the majority of miniscrews used in orthodontic treatment are inserted in the maxillary buccal region for retraction of the anterior teeth. The right side was chosen because a previous study showed that the right side is more at risk of experiencing miniscrew failure due to infection and inflammation [12]. Peri-miniscrew plaque was collected from the miniscrew neck surface using a sterile absorbent paper point (Dentplus \#35). The paper points were swabbed clockwise around the miniscrew's neck, as shown in Fig. 1 and then stored in $1000-\mu \mathrm{L}$ of phosphate-buffered saline in an Eppendorf tube. Subsequently, all the samples were refrigerated at $-20^{\circ} \mathrm{C}$ until laboratory processing.

\section{Laboratory procedure and materials}

DNA was extracted and purified from each sample using GENEzol ${ }^{\mathrm{TM}}$ reagent by following the instructions of the manufacturer. The DNA concentration of each sample was measured using Qubit fluorometry. The Qubit ${ }^{\circledR}$ dsDNA HS (high-sensitivity) assay kit was used as Qubit reagent. The concentration of DNA was standardized to $100 \mathrm{ng} / \mu \mathrm{L}$ using nuclease-free water.

The bacterial counts in plaque samples were evaluated by real-time PCR qPCR. qPCR was used in this study because it is effective, efficient, reproducible, and sensitive for detecting periodontopathogenic bacteria [13]. All reactions were performed using the Step One Plus qPCR system (Applied Biosystems, Foster City, CA, USA) and SensiFAST $^{\mathrm{TM}}$ SYBR $^{\circledR}$ Hi-Rox kit. The primers used for qPCR are displayed in Table 1.

qPCR was performed in a final volume of $10 \mu \mathrm{L}$, consisting of $5 \mu \mathrm{L}$ of SensiFAST ${ }^{\mathrm{TM}} \mathrm{SYBR}^{\circledR} \mathrm{Hi}$-Rox, $0.5 \mu \mathrm{L}$ of forward primers, $0.5 \mu \mathrm{L}$ of reverse primers, and $4 \mu \mathrm{L}$ of target template. The thermal profile consisted of initial denaturation at $95^{\circ} \mathrm{C}$ for $10 \mathrm{~min}$, followed by 40 cycles of denaturation at $95^{\circ} \mathrm{C}$ for $15 \mathrm{~s}$ and annealing/extension at $60^{\circ} \mathrm{C}$ for 1 min $[14,15]$. Each cycle-threshold (CT) of every sample was obtained at the end of qPCR. The CT mean value was inserted into a standard curve equation determined previously and $2^{-\Delta \Delta \mathrm{ct}}$ for relative quantification. The standard curve of total bacteria was generated from the known colony-forming unit (CFU/mL) of Escherichia coli serial dilution. The CT was measured and plotted against the $\log _{10}$ of the copy number. The equation of total bacteria was obtained from the standard curve resulting from qPCR, as shown in Fig. 2.

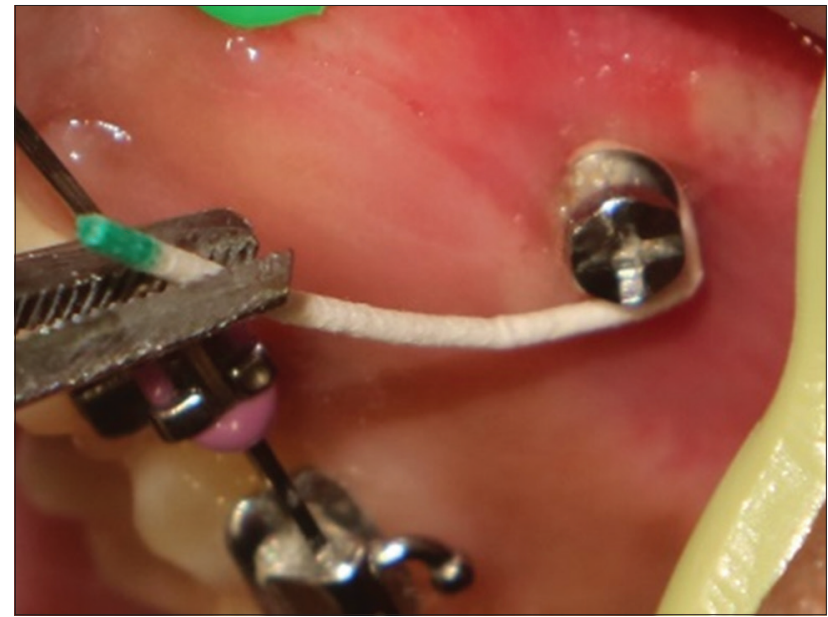

Fig. 1: Conducting bacteria sample collection from the miniscrew neck

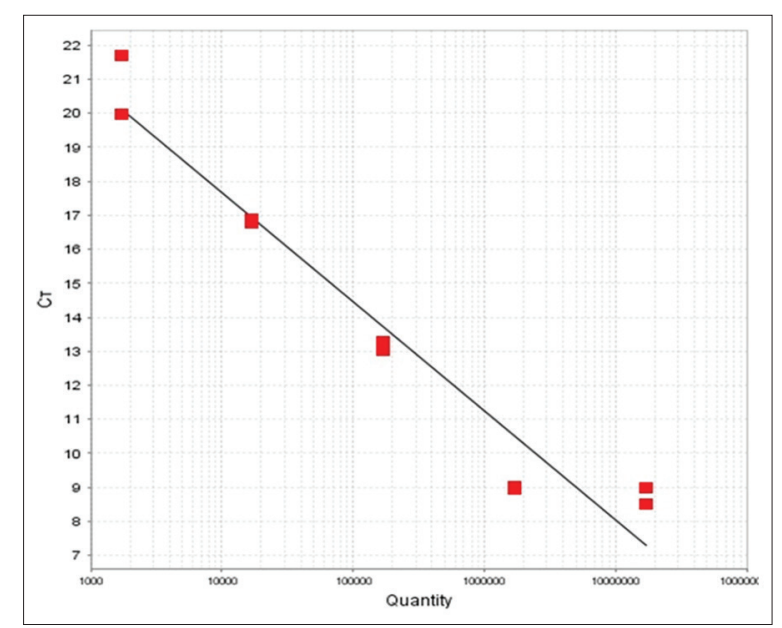

Fig. 2: Standard curve for total bacteria; cycle-threshold $=-3.02$ (log quantity) + 30,461; $R^{2}=0.994$

Table 1: Primers used in this study

\begin{tabular}{lll}
\hline Bacteria & Sequence of primers (5'-3') & $\begin{array}{l}\text { Target } \\
\text { gene }\end{array}$ \\
\hline $\begin{array}{l}\text { Universal [14] } \\
\text { (total bacteria) }\end{array}$ & $\begin{array}{l}\text { Forward, TTA AAC TCA AAG } \\
\text { GAA TTG ACG G } \\
\text { Reverse, CTC ACG ACA CGA }\end{array}$ & 16S rRNA \\
& GCT GAC GAC & \\
Porphyromonas & Forward, TAC CCA TCG & 16S rRNA \\
Gingivalis [15] & TCG CCT TGG T & \\
& Reverse, CGG ACT AAA & \\
Tannerella & ACC GCA TAC ACT TG & 16S rRNA \\
forsythia [15] & Rerward, ATC CTG GCT CAG GAT & \\
Treponema & Forward, AGA GCA AGC & \\
Denticola [15] & TCT CCC TTA CCG & \\
& Reverse, TAA GGG CGG & \\
& CTT GAA ATA ATG & \\
\hline
\end{tabular}

\section{Statistical analysis}

All statistical analyses were performed using the Statistical Package for the Social Sciences version 22 software program (IBM Corp., Armonk, NY, USA). Univariate analysis was performed to obtain the mean, standard deviation, minimum, and maximum values of all parameters. Quantitative differences of total bacteria before and after rinsing 
treatment were assessed using the Wilcoxon test because the data varied significantly from a normal distribution $(\mathrm{p}<0.05)$. The differences in total bacteria and red-complex bacteria quantity alteration between the chlorhexidine, chitosan, and Aquadest groups were assessed using the Kruskal-Wallis test because the data varied significantly from a normal distribution $(\mathrm{p}<0.05)$.

\section{RESULTS AND DISCUSSION}

\section{Peri-miniscrews clinical condition}

Thirty patients ( 25 women and five men) according to the inclusion criteria underwent the complete procedure in this study with no complications. Subjects' ages ranged from 15 to 33 years $(23.3 \pm 4.7)$. From 30 patients, 53 miniscrews inserted in various locations were evaluated for clinical signs of peri-miniscrew inflammation. Fig. 3 shows the distribution of clinical signs found from peri-miniscrews involved in this study.

Among all miniscrews implanted, 34 miniscrews' implantation sites (64.15\%) were healthy; two miniscrews' implantation sites (3.77\%) showed signs of peri-implantitis (e.g., mobility, pain, swelling, and redness); three miniscrews' implantation sites (5.66\%) showed swelling, redness, and pain only; eight miniscrews' implantation sites $(15.09 \%)$ showed swelling and redness; and six miniscrews' implantation sites (11.33\%) showed redness of peri-miniscrew tissue.

Infection and inflammation in peri-miniscrew tissue need to be controlled to prevent the functional failure of the miniscrew implant as an anchorage device in orthodontic treatment. Although microbial infection is not the only causative factor of miniscrew failure, several studies have stated that infection and inflammation in relation to peri-miniscrew implantation are related to the miniscrew failure rate [16-19]. Osório et al. [20] confirmed that microbial colonization occurred in the first $24 \mathrm{~h}$ after exposure of miniscrew implants to the oral cavity, and the nature of microbial colonization did not change significantly if miniscrew hygiene was controlled.

One of the 30 plaque samples evaluated with qPCR showed clinical symptoms of peri-implantitis, including redness, swelling, pain, and mobility of the miniscrew. Peri-miniscrew infection is a main factor leading to miniscrew failure $[16,19,21]$. The results of qPCR demonstrated the detection of three red-complex bacteria in a periminiscrew plaque sample included in the chlorhexidine group. After using the chlorhexidine mouthwash twice a day for 4 days, peri-miniscrew swelling was observed to have subsided but the mobility, pain, and redness were seen to remain. The reduced clinical symptoms and bacterial counts in this peri-implantitis case indicate that chlorhexidine can be used to treat peri-implantitis even though miniscrew mobility cannot always be overcome immediately.

\section{Total bacteria quantification}

One sample from each subject was evaluated with qPCR to obtain the quantity of peri-miniscrew bacteria. The results indicated a reduction in total bacteria count occurred in all groups after 4 days rinsing, as shown in Fig. 3. Normality testing using the Shapiro-Wilk test revealed that the data varied significantly from normal distribution $(\mathrm{p}<0.05)$. The Wilcoxon test showed that the number of total bacteria colonies was reduced significantly in both the chlorhexidine and chitosan groups but not in the control (Aquadest) group. This result supports that chlorhexidine and chitosan are effective as antibacterial agents to reduce the total bacteria around the miniscrew. The comparison of total bacteria reduction before and after 4 days of rinsing is shown in Fig. 4. The quantity of total bacteria reduction and the p-values from the Wilcoxon test are shown in Table 2.

The outcomes of Kruskal-Wallis testing among rinsing groups showed $\mathrm{p}<0.05(\mathrm{p}=0.038)$, which meant that the difference was statistically significant. Post hoc analysis using the Mann-Whitney U-test supported that the total bacteria count after rinsing differed significantly between the chlorhexidine and control groups $(p=0.041)$. Moreover, the

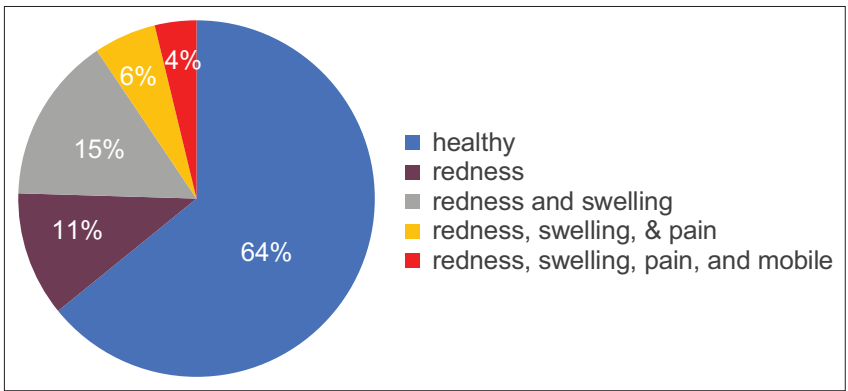

Fig. 3: Peri-miniscrew clinical condition

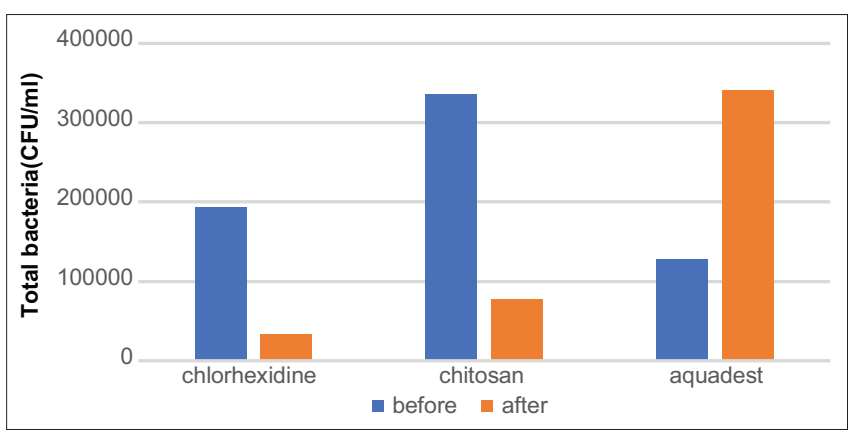

Fig. 4: The total bacteria before and after 4 days of rinsing

Table 2: Total bacteria count reduction

\begin{tabular}{lllll}
\hline Mouthwash & $\begin{array}{l}\text { Total } \\
\text { bacteria } \\
\text { count before } \\
\text { rinsing }\end{array}$ & $\begin{array}{l}\text { Total } \\
\text { bacteria } \\
\text { count after } \\
\text { rinsing }\end{array}$ & $\begin{array}{l}\text { Total } \\
\text { bacteria } \\
\text { count } \\
\text { changes }\end{array}$ & $\begin{array}{l}\text { p-value } \\
\text { (Wilcoxon } \\
\text { test) }\end{array}$ \\
\hline Chlorhexidine & 192.409 & 33.830 & -167.551 & $0.037^{*}$ \\
Chitosan & 336.109 & 77.578 & -202.407 & $0.028^{*}$ \\
Aquadest & 127.630 & 341.405 & 137.686 & 0.285 \\
\hline
\end{tabular}

Negative values indicate a reduction after treatment. ${ }^{*} \mathrm{p}<0.05=$ significant

mean differed significantly between the chitosan and control groups $(p=0.019)$. However, the total bacteria count after rinsing was not significantly different between the chlorhexidine and chitosan groups $(p=0.821)$. These results suggest that chitosan was as effective as chlorhexidine in reducing the total bacteria count.

\section{Red-complex bacteria quantification}

The effects of chlorhexidine, chitosan, and Aquadest rinsing on redcomplex bacteria were evaluated using relative quantification with the $2^{-\Delta \Delta C t}$ method [22]. Delta Ct $(\Delta \mathrm{Ct})$ values in this study were obtained from differences between $\mathrm{Ct}$ values of target genes and total bacteria from the same sample. $\Delta \Delta \mathrm{Ct}$ values were obtained from differences between $\Delta \mathrm{Ct}$ before and after 4 days of rinsing treatment. The results showed that the chlorhexidine group presented reductions of $55.8 \%$ in P. gingivalis count, $25.3 \%$ in T. forsythia count, and $42.6 \%$ in T. denticola count. In the chitosan group, the reductions were $26 \%$ in $P$. gingivalis count, $17.1 \%$ in $T$. forsythia count, and $58.11 \%$ in T. denticola count. In this study, the control group also exhibited a reduction in red-complex bacteria, although the degree of such was quite low. Further, there was a $19.5 \%$ reduction in P. gingivalis, $18.8 \%$ reduction in T. forsythia, and $2.7 \%$ reduction of $T$. denticola in the control group. The comparison among bacteria count reduction between rinsing groups for each redcomplex bacteria is shown in Figs. 5-7.

The results of qPCR showed a decrease in the total number of bacteria as well as specifically P. gingivalis, T. forsythia, and T. denticola after the use of chlorhexidine mouthwash. Apel et al. [23] investigated the microflora associated with failed and successful miniscrew cases, finding that 


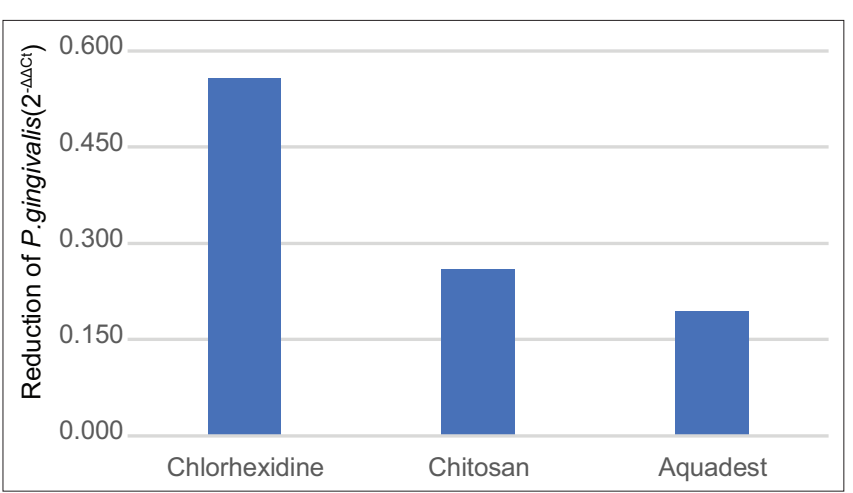

Fig. 5: The effect of chlorhexidine, chitosan, and Aquadest on Porphyromonas gingivalis count reduction

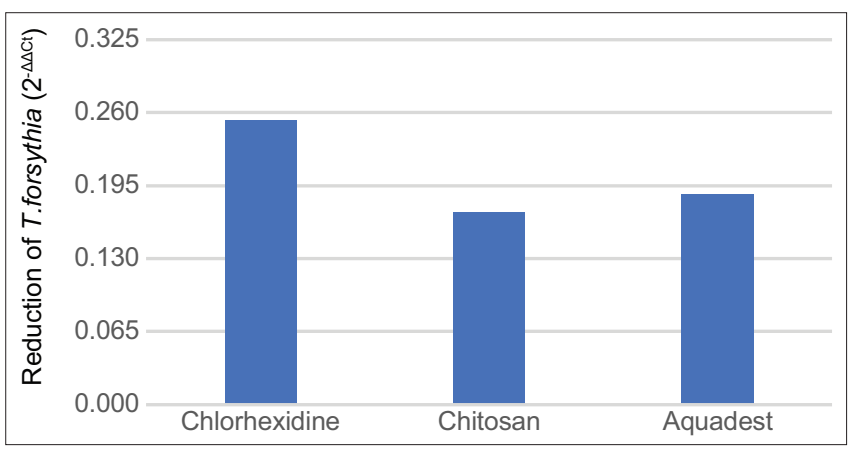

Fig. 6: The effect of chlorhexidine, chitosan, and Aquadest on Tannerella forsythia count reduction

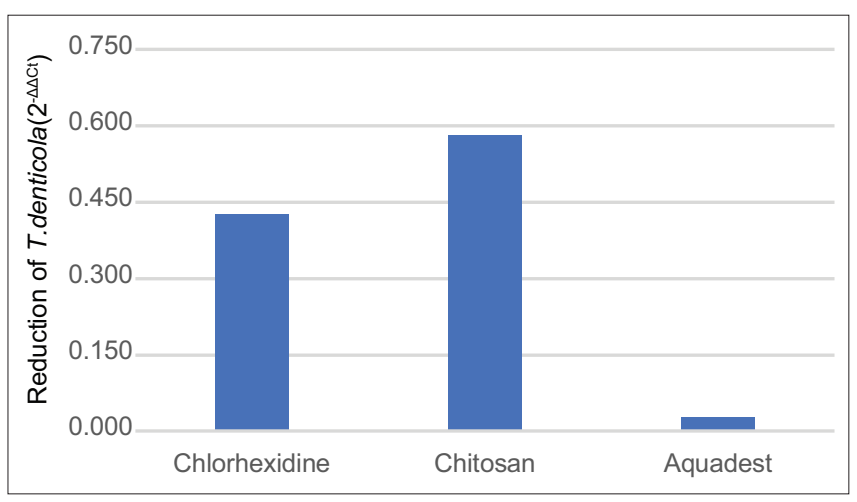

Fig. 7: The effect of chlorhexidine, chitosan, and Aquadest on Treponema denticola count reduction

P. gingivalis was not found in either healthy or failed miniscrews, but T. forsythia was found in $25 \%$ of failed miniscrews but no healthy miniscrews. In the present study, one out of 30 miniscrews exhibited clinical signs of peri-miniscrew implantitis (e.g., mobility, pain, swelling, and redness) as explained by Monga et al. [11]. Different from in the study by Apel et al. [23], in this investigation, all red-complex bacteria including P. gingivalis, T. forsythia, and T. denticola were detected periminiscrew with accompanying peri-implantitis clinical signs.

The present study also shows that chitosan has a comparable level of antibacterial activity to that of chlorhexidine in reducing the total bacteria count, including specifically against T. denticola. However, the antibacterial activity of chitosan against both $P$. gingivalis and T. forsythia was not significantly different from that of the control group (Aquadest) in this study. The Aquadest group in this study represented placebo rinsing, which has no antibacterial effect. This result showed that the chitosan solution in this study was not effective in reducing
P. gingivalis or T. forsythia. In contrast, recent studies have revealed that chitosan possesses antibacterial activity against Gram-positive bacteria, Gram-negative bacteria, and fungi $[8,9,24]$.

\section{Chitosan antibacterial modes of action}

The antibacterial activity of chitosan is influenced by its DD, MW, and acidity $(\mathrm{pH})[8,25]$. The characteristics of chitosan used in this study are DD: $85 \%$, high $\mathrm{MW}$, and $\mathrm{pH}: 6$. There are several chitosan modes of action against bacteria cells. One of the modes of action is to disrupt bacterial cell membranes by provoking electrostatic interaction between the positive charges of chitosan and negative charges of the cell membrane [8]. The high-DD chitosan used in this study means that this chitosan has a high number of positive charges with which to interact with anionic parts of the lipopolysaccharides on bacterial cell membranes. This electrostatic interaction between chitosan and lipopolysaccharide leads to disruption of the cell membrane. Another chitosan mode of action involves penetrating the bacterial cell membrane [8]. The high-molecular-weight chitosan used in this study probably inhibited the ability of chitosan molecules to get inside the bacterial cells, especially those of Gram-negative bacteria, which have double membranes. This explains the inadequacy of chitosan to reduce the counts of $P$. gingivalis and T. forsythia in this study. The better antibacterial activity of chitosan on T. denticola relative to P. gingivalis and T. forsythia in the present study is allegedly due to the long helicalshaped morphology of T. denticola. The long helical shape of T. denticola means there is a wider membrane surface area that can interact with positive charges of chitosan as compared short rod-shaped P. gingivalis and T. forsythia. In the future study, it is recommended to use high DD chitosan with low MW or nanoparticle to evaluate its potential antibacterial value, especially on Gram-negative bacteria.

However, some limitations in this study should be noted. First, this study involved a limited amount of sample with a high variation of clinical condition of peri-miniscrew before treatment that may influence the result. Second, the oral hygiene standard of subjects was not controlled, which would bias the results. Nonetheless, the results of this study showed that chitosan is a potential antibacterial agent to be used as an active ingredient in mouthwash and further studies is required.

\section{CONCLUSION}

This study reveals that chitosan has adequate antibacterial activity to reduce the total bacteria count peri-miniscrew and its effectiveness does not significantly differ from that of chlorhexidine. The antibacterial activity of chitosan on red-complex bacteria still needs to be evaluated. Nonetheless, chitosan has a potential antibacterial activity to be incorporated into mouthwash to maintain peri-miniscrew hygiene.

\section{ACKNOWLEDGMENT}

This research was financially supported by Hibah Kompetitif Publikasi Internasional Terindeks Tugas Akhir (PITTA) from the Directorate of Research and Community Engagement, Universitas Indonesia. The authors wish to thank Dr. Dra. Pipih Suptijah, MBA for information about chitosan, suggestions, and support during the research.

\section{CONFLICTS OF INTEREST}

The authors report no conflicts of interest.

\section{REFERENCES}

1. Jasoria G, Shamim W, Rathore S, Kalra A, Manchanda M, Jaggi N. Miniscrew implants as temporary anchorage devices in orthodontics: A comprehensive review. J Contemp Dent Pract 2013;14:993-9.

2. Papadopoulos MA, Tarawneh F. Miniscrew implants for temporary skeletal anchorage in orthodontic treatment. In: Skeletal Anchorage in Ortodontic Treatment of Class II Malocclusion. New York: Elsevier, Mosby; 2015. p. 58-65.

3. Kravitz ND, Kusnoto B. Risks and complications of orthodontic miniscrews. Am J Orthod Dentofac Orthop 2007;131 Suppl 4:43-51.

4. Sato R, Sato T, Takahashi I, Sugawara J, Takahashi N. Profiling of 
bacterial flora in crevices around titanium orthodontic anchor plates. Clin Oral Implants Res 2007;18:21-6.

5. Tallarico M, Canullo L, Caneva M, Özcan M. Microbial colonization at the implant-abutment interface and its possible influence on periimplantitis: A systematic review and meta-analysis. J Prosthodont Res 2017;61:233-41.

6. Balagopal S, Arjunkumar R. Chlorhexidine: The gold standard antiplaque agent. J Pharm Sci Res 2013;5:270-4.

7. Gürgan CA, Zaim E, Bakirsoy I, Soykan E. Short-term side effects of $0.2 \%$ alcohol-free chlorhexidine mouthrinse used as an adjunct to non-surgical periodontal treatment: A double-blind clinical study. J Periodontol 2006;77:370-84.

8. Verlee A, Mincke S, Stevens CV. Recent developments in antibacterial and antifungal chitosan and its derivatives. Carbohydr Polym 2017; 164:268-83.

9. Benhabiles MS, Salah R, Lounici H, Drouiche N, Goosen MF, Mameri N. Antibacterial activity of chitin, chitosan and its oligomers prepared from shrimp shell waste. Food Hydrocoll 2012;29:48-56.

10. Ibrahim B, Suptijah P, Zahid A. Efektivitas kitosan mikrokristalin sebagai alternatif antibakteri alami dalam mouthwash. J Pengolah Has Perikan Indones 2012;15:119-26.

11. Monga N, Chaurasia S, Kharbanda OP, Duggal R, Rajeswari MR. A study of interleukin $1-\beta$ levels in peri-miniscrew crevicular fluid (PMCF). Prog Orthod 2014;15:30.

12. Park HS, Jeong SH, Kwon OW. Factors affecting the clinical success of screw implants used as orthodontic anchorage. Am J Orthod Dentofac Orthop 2006;130:18-25.

13. Kotsilkov K, Popova C, Boyanova L, Setchanova L, Mitov I. Comparison of culture method and real-time PCR for detection of putative periodontopathogenic Bacteria in deep periodontal pockets. Biotechnol Biotechnol Equip 2015;29:996-1002.

14. Sedgley CM, Nagel AC, Shelburne CE, Clewell DB, Appelbe O, Molander A. Quantitative real-time PCR detection of oral Enterococcus faecalis in humans. Arch Oral Biol 2005;50:575-83.

15. Suzuki N, Yoshida A, Nakano Y. Quantitative analysis of multi-species oral biofilms by taqman real-time PCR. Clin Med Res 2005;3:176-85.

16. Ntolou P, Tagkli A, Pepelassi E. Factors related to the clinical application of orthodontic mini-implants. J Int Oral Health 2018;10:103-10.

17. Cheng S, Tseng IY, Lee JJ, Kok SH. A prospective study of the risk factors associated with failure of mini-implants used for orthodontic anchorage. Int J Oral Maxillofac Implants 2004;19:100-6.

18. Miyawaki S, Koyama I, Inoue M, Mishima K, Sugahara T, TakanoYamamoto T. Factors associated with the stability of titanium screws placed in the posterior region for orthodontic anchorage. Am J Orthod Dentofac Orthop 2003;124:373-8.

19. Lyczek J, Antoszewska-Smith J. Fundamental factors related to orthodontic micro-implant stability: Review of the literature. Dent Med Probl 2017:54:189-93.

20. Osório A, De Freitas A, Gonçalves C. Microbial colonization in orthodontic mini-implants. Braz Dent J 2012;23:422-7.

21. Daokar SS, Agarwal G. Orthodontic implant failure: A systematic review. Int J Oral Implantol Clin Res 2016;7:1-6.

22. Livak KJ, Schmittgen TD. Analysis of relative gene expression data using real-time quantitative PCR and the 2- $\Delta \Delta \mathrm{CT}$ method. Methods 2001;25:402-8

23. Apel S, Apel C, Morea C, Tortamano A, Dominguez GC, Conrads G. Microflora associated with successful and failed orthodontic miniimplants. Clin Oral Implants Res 2009;20:1186-90.

24. Jaiswal N, Sinha DJ, Singh UP, Singh K, Jandial UA, Goel S. Evaluation of antibacterial efficacy of chitosan, chlorhexidine, propolis and sodium hypochlorite on Enterococcus faecalis biofilm: An in vitro study. J Clin Exp Dent 2017;9:e1066-74.

25. Younes I, Sellimi S, Rinaudo M, Jellouli K, Nasri M. Influence of acetylation degree and molecular weight of homogeneous chitosans on antibacterial and antifungal activities. Int J Food Microbiol 2014;185:57-63. 